\title{
Targeting Signaling Pathways in Cancer Stem Cells for Cancer Treatment
}

\author{
Jeffrey Koury, ${ }^{1}$ Li Zhong, ${ }^{2,3}$ and Jijun Hao ${ }^{1,4}$ \\ ${ }^{1}$ Graduate College of Biomedical Sciences, Western University of Health Sciences, Pomona, CA 91766, USA \\ ${ }^{2}$ Department of Cell Biology, College of Life Sciences, Hebei University, Baoding, Hebei, China \\ ${ }^{3}$ Department of Basic Medical Sciences, College of Osteopathic Medicine of the Pacific, Western University of Health Sciences, \\ Pomona, CA, USA \\ ${ }^{4}$ College of Veterinary Medicine, Western University of Health Sciences, Pomona, CA 91766, USA
}

Correspondence should be addressed to Jijun Hao; jhao@westernu.edu

Received 2 December 2016; Revised 10 February 2017; Accepted 13 February 2017; Published 5 March 2017

Academic Editor: Shimon Slavin

Copyright (C) 2017 Jeffrey Koury et al. This is an open access article distributed under the Creative Commons Attribution License, which permits unrestricted use, distribution, and reproduction in any medium, provided the original work is properly cited.

\begin{abstract}
The Wnt, Hedgehog, and Notch pathways are inherent signaling pathways in normal embryogenesis, development, and hemostasis. However, dysfunctions of these pathways are evident in multiple tumor types and malignancies. Specifically, aberrant activation of these pathways is implicated in modulation of cancer stem cells (CSCs), a small subset of cancer cells capable of self-renewal and differentiation into heterogeneous tumor cells. The CSCs are accountable for tumor initiation, growth, and recurrence. In this review, we focus on roles of Wnt, Hedgehog, and Notch pathways in CSCs' stemness and functions and summarize therapeutic studies targeting these pathways to eliminate CSCs and improve overall cancer treatment outcomes.
\end{abstract}

\section{Introduction}

Cancer stem cells (CSCs) are a small subset of cancer cells with the capability of self-renewal and differentiation into heterogeneous tumor cells, and they have been believed to be responsible for tumor initiation, growth, and recurrence. The first population of CSCs was identified in human acute myeloid leukemia (AML), where they displayed strong tumorigenic ability in an in vivo mouse model $[1,2]$. Subsequently, many laboratories across the globe have been able to capture and propagate CSCs from a variety of human tumors including brain cancer, melanoma and breast cancer, liver cancer, pancreatic cancer, colon cancer, and prostate cancer [3-9]. As CSCs can survive traditional cancer therapies and result in tumor recurrence and drug resistance [10-12], eradication of CSCs in tumors may represent an effective anticancer therapeutic strategy. Towards this goal, significant efforts have been made to explore the signaling mechanisms underlying CSCs' self-renewal and differentiation, as well as development of regimens targeting the CSCs. In this review, we focus on three key evolutionarily conserved CSC signaling pathways (Wnt, Hedgehog, and Notch pathways) and therapeutic strategies disrupting CSCs' stemness and functions by modulating these pathways.

\section{Signaling Pathways in CSCs}

In the past, multiple CSC models have been proposed for tumor heterogeneity including the classical CSC unidirectional differentiation model and the plastic CSC bidirectional dedifferentiation model $[13,14]$ (Figure 1). In the classical CSC unidirectional differentiation model, CSCs differentiate to non-CSC tumor cells that are unable to move back up the hierarchy to acquire CSC-like activity; however, in the plastic CSC bidirectional dedifferentiation model, non-CSC tumor cells can undergo a dedifferentiation process and acquire CSC-like properties, presumably through epithelialmesenchymal transition (EMT) in carcinoma [15-19]. Nevertheless, in either CSC model, Wnt, Hedgehog, and Notch pathways are considered important CSCs' regulators.

2.1. Canonical Wnt Signaling Pathway. Canonical Wnt pathway, in which Wnt ligands signal through $\beta$-catenin for their biological functions, is a critical evolutionarily conserved 

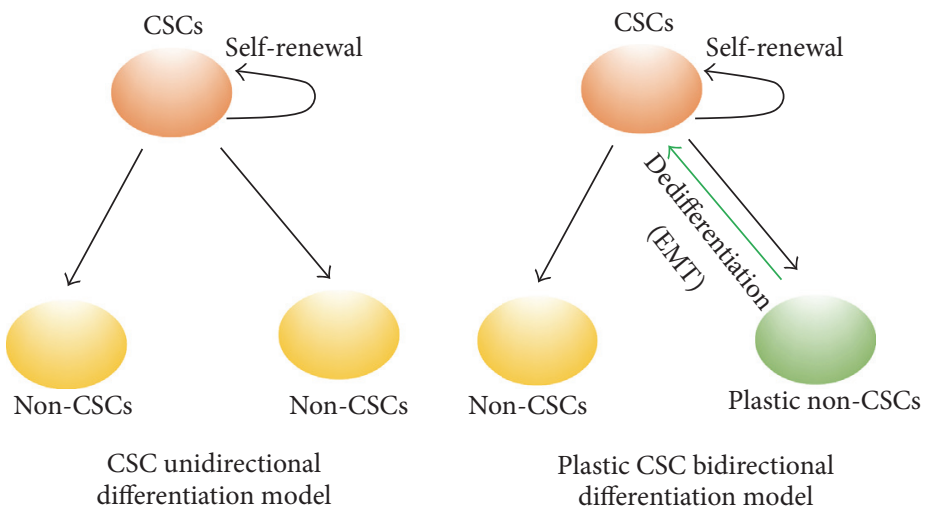

FIGURE 1: A schematic outlining the classical CSC unidirectional differentiation model and the plastic CSC bidirectional dedifferentiation model. In the unidirectional differentiation model, CSCs preexist in the tumor environment and solely self-renew or differentiate into the non-CSC tumor cells. However, in the plastic CSC bidirectional model, the plastic non-CSC tumor cells can dedifferentiate to acquire a CSC phenotype via epithelial-mesenchymal transition (EMT).

(a)

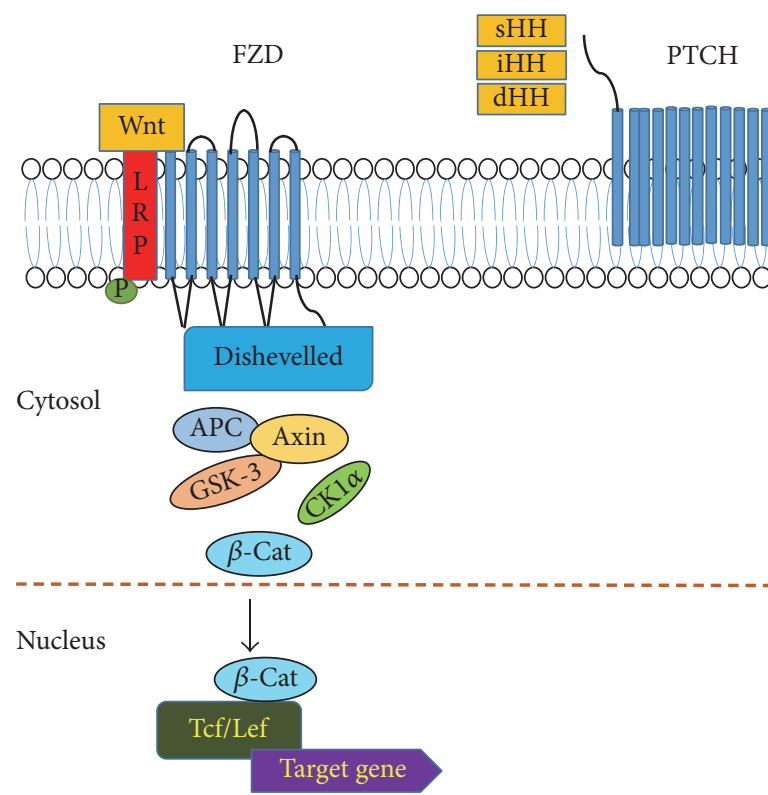

(b) 
TABLE 1: Small molecule/biological therapeutics targeting the Wnt pathway.

\begin{tabular}{|c|c|c|c|c|}
\hline Molecule & Function & $\begin{array}{c}\text { Phase/clinical } \\
\text { trials }\end{array}$ & Cancer type & NCT Number \\
\hline PRI-724 & Dishevelled inhibitor & Phase $1 / 2$ & $\begin{array}{l}\text { Pancreatic cancer, acute myeloid } \\
\text { leukemia, and colon cancer }\end{array}$ & $\begin{array}{l}\text { NCT02413853 } \\
\text { NCT01606579 } \\
\text { NCT01764477 } \\
\end{array}$ \\
\hline LGK974 & Porcupine inhibitor & Phase 1 & $\begin{array}{c}\text { Melanoma, breast cancer, and } \\
\text { pancreatic adenocarcinoma }\end{array}$ & NCT01351103 \\
\hline $\begin{array}{l}\text { Vantictumab } \\
\text { (OMP18R5) }\end{array}$ & Anti-Frizzled 7 receptor & Phase $1 \mathrm{~b}$ & $\begin{array}{l}\text { HER2 negative breast cancer and } \\
\text { pancreatic cancer }\end{array}$ & NCT01345201 \\
\hline $\begin{array}{l}\text { Ipafricept } \\
\text { (OMP-54F28) }\end{array}$ & Fc-Frizzled 8 receptor & Phase $1 \mathrm{a} / 1 \mathrm{~b}$ & Pancreatic cancer and ovarian cancer & $\begin{array}{r}\text { NCT02092363 } \\
\text { NCT02050178 } \\
\end{array}$ \\
\hline
\end{tabular}

The clinical trial information was accessed via https://clinicaltrials.gov with National Clinical TrialNumber (NCT Number).

cancer, breast cancer, hematologic cancer, skin cancer, and lung cancer [23-27]. For instance, in colorectal cancer, Wnt signaling deregulation is often associated with mutations in APC and $\beta$-catenin genes [28]. Mutations in APC have been found in around $80 \%$ of all human colon tumors, and these mutations inactivate APC function resulting in Wnt signaling activation by preventing $\beta$-catenin phosphorylation and subsequent $\beta$-catenin degradation $[29,30]$. In addition, $\beta$-catenin oncogenic mutations have been reported in approximately $10 \%$ of colorectal cancer patients, and these missense or deletion mutations are located at $\beta$-catenin sites where GSK $3 \beta$ normally phosphorylates $\beta$-catenin, leading to stable $\beta$-catenin translocation into the nucleus for Wnt activation [22, 31]. Abnormal activation of Wnt signaling disrupts the normal growth and differentiation of colonic crypt stem cells, resulting in a colorectal CSC phenotype by upregulating expression of target genes such as $c-m y c$ and cyclin $\mathrm{D}[22,32]$. Moreover, in a recent comparative analysis of signaling pathways between the $\mathrm{CD}^{44+} / \mathrm{CD}^{133+}$ colorectal CSCs and $\mathrm{CD}^{44-} / \mathrm{CD}^{133-}$ cancer cells, Wnt pathway was shown to be highly associated with $\mathrm{CD}^{44+} / \mathrm{CD}^{133+}$ colorectal CSCs [33].

In addition to colorectal CSCs, Wht signaling is also involved in other types of cancer CSCs. For example, in an elegant study of squamous cell carcinomas, canonical Wnt signaling activation was shown to be critical in tumorigenesis of $\mathrm{CD}^{34+}$ bulge CSCs, and ablation of the $\beta$-catenin gene resulted in depletion of $\mathrm{CD}^{34+} \mathrm{CSCs}$ and complete tumor regression in mice [27]. In addition, $\beta$-catenin-deficient tumor cells devoid of the $\mathrm{CD}^{34+} \mathrm{CSC}$ s were unable to propagate secondary tumors, and conversely tamoxifen-induced expression of a nondegradable $\beta$-catenin in the skin sufficiently expanded the bulge CSC's population [27].

Moreover, dedifferentiation through EMT is a critical step for non-CSC tumor cells to acquire CSC-like properties as defined by the plastic CSC bidirectional model. Wnt signaling plays an important role in this cancer cell dedifferentiation. One study showed that experimental knockdown of CD146 can dedifferentiate colorectal cancer cells to acquire a stem cell phenotype through inhibiting GSK-3 $\beta$ which in turn promoted nuclear translocation of $\beta$-catenin for Wnt signaling activation [34]. Therefore, modifying Wnt signaling may be essential in the pursuit to curb colorectal cancer, specifically colorectal cancer stem cells.

2.1.2. Therapeutic Agents Targeting Wnt Signaling. As Wnt signaling activation is implicated in CSC's self-renewal, tumorigenesis, and cancer cell dedifferentiation into CSCs, targeting CSCs by inhibiting the Wnt signaling may be a promising therapeutic approach for cancer. Recently numerous Wnt signaling inhibitors, including biological agents and small molecule agents, have been developed [35]. However, to date, no Wnt signaling inhibitors have been approved for clinical usage. The majority of Wnt inhibitors have been evaluated preclinically, and the readers can refer to our recent review paper in this area [35]. Here we summarize ongoing clinical trials of Wnt inhibitors (Table 1). For instance, one clinical trial of a Wnt inhibitor is PRI-724 which inhibits the Wnt signaling by specifically binding to downstream CREB-binding protein. PRI-724 was previously shown to induce apoptosis of colon carcinoma cells and exhibit antitumor activity in the mouse xenograft models of colon cancer [36]. In the phase I trial, 18 patients were treated showing favorable toxicity profiles with only one dose-limiting toxicity of grade 3 of reversible hyperbilirubinemia [37]. An impending phase II trial for PRI-724 is almost underway involving mFOLFOX6/Bevacizumab with or without PRI-724. The focus of the study is to target patients with Stage IV metastatic colorectal cancer (NCT Number: NCT02413853). In addition, Porcupine is a membrane bound O-acyltransferase (MBOAT) specific to Wnt posttranslational acylation, which is required for subsequent Wnt secretion, and loss of Porcupine can lead to Wnt signaling inhibition $[38,39]$. In addition, a specific small molecular Porcupine inhibitor LGK974 was identified in a luciferasebased cell screening and was efficacious in targeting Wnt signaling in multiple tumor models including murine and rat mechanistic breast cancer models and a human head and neck squamous cell carcinoma model [40]. Recently, a phase I, open label dose escalation trial of the LGK974 has been initiated to treat a variety of malignancies including melanoma, breast cancer, and pancreatic adenocarcinoma (NCT Number: NCT01351103). Other than small molecules, several biologic therapeutic agents targeting the Wnt pathway 
have entered clinical trials as well (Table 1). For instance, OMP18R5 (also known as Vantictumab), a fully humanized monoclonal antibody that targets FZD receptor, has recently concluded an open label phase 1 dose escalation study for solid tumors [41, 42] (NCT Number: NCT01345201). Another biologic therapeutic agent OMP-54F28, a fusion protein that binds Wnt ligands and prevents them from binding to FZD receptors, was recently developed. In phase I trial of OMP$54 \mathrm{~F} 28$, minimum doses at $0.5 \mathrm{mg} / \mathrm{kg}$ ranging up towards $10 \mathrm{mg} / \mathrm{kg}$ were administered intravenously once every 3 weeks in patients with solid tumors (NCT Number: NCT01608867). Although this clinical trial has recently been completed, the results have not been announced publicly [41, 42]. Moreover, another two phase $1 \mathrm{~b}$ trials are underway involving OMP-54F28 and the chemotherapy drug Paclitaxel to treat ovarian and Stage IV pancreatic cancer (NCT Numbers: NCT02092363, NCT02050178).

2.2. Hedgehog Signaling. $\mathrm{HH}$ signaling is essential in a wide variety of cellular and molecular processes during embryogenesis, development, and adult tissue homeostasis [43, 44]. Three Hedgehog homologues, Sonic Hedgehog ( $\mathrm{sHH}$ ), Indian Hedgehog $(\mathrm{iHH})$, and Desert Hedgehog $(\mathrm{dHH})$, have been well studied in mammals $[45,46]$. In the absence of $\mathrm{HH}$ ligands, a cell-surface transmembrane protein Patched $(\mathrm{PTCH})$ inhibits the transmembrane protein Smoothened (SMO), and full length GLI proteins are then proteolytically processed to generate the repressor $\mathrm{GLI}^{\mathrm{R}}$ to suppress $\mathrm{HH}$ signaling target gene expression (Figure 2). However, when extracellular $\mathrm{HH}$ ligands bind to PTCH, PTCH's inhibitory influence on SMO is removed, and activation of SMO results in nuclear translocation of GLI and induction of $\mathrm{HH}$ signaling target gene transcription $[45,47]$.

2.2.1. Abnormal HH Signaling Activation and CSCs. Aberrant activation of the $\mathrm{HH}$ pathway in CSC's regulation and maintenance has been reported in numerous cancer types including glioblastoma, lung squamous cell carcinoma, breast cancer, pancreatic adenocarcinoma, myeloma, and chronic myeloid leukemia (CML) [48-53]. In multiple myeloma CSCs, it was shown that SMO and Glil were highly expressed in comparison to non-CSCs, and activation of $\mathrm{HH}$ signaling by $\mathrm{HH}$ ligands promoted multiple myeloma CSC's expansion, whereas inhibition of the $\mathrm{HH}$ signaling markedly blocked CSC's clonal expansion [54]. The data supports that $\mathrm{HH}$ signaling promotes multiple myeloma CSC's functions. Moreover, higher activation of $\mathrm{HH}$ signaling was also observed in CSCs of human lung squamous cell carcinoma and glioma as compared to bulk tumor cells, further supporting aberrant $\mathrm{HH}$ signaling activation's critical role for CSC selfrenewal and regulation $[49,53]$. In another study, Zhao et al. reported that $\mathrm{HH}$ pathway activation was also involved in maintenance of CML CSCs [52]. In a murine CML model of study, deletion of SMO significantly reduced the CML CSCs, and conversely overexpression of SMO in a SMO-deficient mouse CML model dramatically enhanced CML CSCs 4fold and significantly increased CML progression [52]. In addition, inhibition of $\mathrm{HH}$ signaling by SMO antagonist cyclopamine reduced a glioblastoma stem cells population
[50], and similar findings have been observed in colon CSCs, pancreatic CSCs, prostate CSCs, and lung CSCs [55-58].

In the plastic CSC bidirectional dedifferentiation model, $\mathrm{HH}$ signaling plays an important role during the EMT process to acquire stem cell-like phenotypes. For instance, Glil was shown to correlate with markers of EMT and highly express in the claudin-low breast CSCs, and knockdown of Glil resulted in reduced claudin-low breast CSC's viability, motility, clonogenicity, and self-renewal as well as tumor growth in orthotopic xenografts [59]. Recently, Wang et al. have demonstrated that $\mathrm{HH}$ pathway and EMT are active in pancreatic cancer cells-derived tumorspheres that exhibit CSC properties, and inhibition of $\mathrm{HH}$ signaling by SMO knockdown blocks the self-renewal, EMT, invasion, chemoresistance, and tumorigenesis of pancreatic CSCs [60].

2.2.2. Therapeutic Agents Targeting HH Signaling. As evidenced above, HH signaling plays a critical role in CSC's selfrenewal and regulation, and inhibition of the $\mathrm{HH}$ pathway disrupts CSC's stemness and induces CSC's differentiation which are desirable for cancer treatment. In the past, numerous $\mathrm{HH}$ pathway inhibitors have been developed. For a complete review of $\mathrm{HH}$ signaling inhibitors, please refer to the recent reviews [61-63]. Here we only summarize the $\mathrm{HH}$ signaling inhibitors either approved by FDA or under clinical trials (Table 2). Vismodegib developed by Genentech is the first $\mathrm{HH}$ signaling inhibitor approved by FDA. Vismodegib targets SMO for $\mathrm{HH}$ signaling inhibition and has been used to treat metastatic basal cell carcinoma. The initial phase I trial of Vismodegib showed that 18 out of 33 enrolled patients with locally advanced or metastatic tumors had a response to Vismodegib. Among the remaining 15 patients, 11 had stable disease for up to 10.8 months and 4 had progressive disease. No dose-limiting toxic effects or grade 5 adverse events were seen in the trial and reported toxicities were mild with common side effects of mild loss of taste, hair loss, weight loss, and hyponatremia [64, 65]. Currently, clinical trials of Vismodegib as a monotherapy or in combination with other therapeutic drugs are ongoing for various cancers including medulloblastoma, small cell lung cancer, metastatic pancreatic cancer, metastatic prostate cancer, intracranial meningioma, recurrent glioblastoma, and acute myeloid leukemia (NCT Numbers: NCT00833417, NCT01201915, NCT00739661, and NCT01088815) [61]. In 2015, a new SMO inhibitor, Sonidegib, was approved by the FDA to treat adult patients with locally advanced BCC. In the dose escalation phase I trial, maximum tolerated doses of $800 \mathrm{mg}$ daily and $250 \mathrm{mg}$ twice daily were established [66]. Grade 1/2 adverse effects were apparent, consisting of nausea, anorexia, vomiting, muscle spasms, fatigue, and alopecia and grade $3 / 4$ adverse effects were weight loss, hyperbilirubinemia, myalgia, fatigue, and dizziness (NCT Number: NCT01529450) [66]. A phase II study demonstrated that Sonidegib sustained tumor responses in patients with advanced BCC after a 12-month follow-up [67]. Currently several phase I/II trials of Sonidegib to treat other solid tumors and hematological malignancies are still underway (NCT Numbers: NCT02195973, NCT01487785) [61]. Moreover, a few of $\mathrm{HH}$ signaling inhibitors that are actively being 
TABLE 2: Small molecule/biological therapeutics targeting the Hedgehog pathway.

\begin{tabular}{|c|c|c|c|c|}
\hline Molecule & Function & $\begin{array}{l}\text { Phase/clinical } \\
\text { trials }\end{array}$ & Cancer type & NCT Number \\
\hline $\begin{array}{l}\text { GDC-0 } 0449 \\
\text { (Vismodegib } \\
\text { derivative) }\end{array}$ & SMO inhibitor & Phase 2 & $\begin{array}{c}\text { Basal cell carcinoma, ovarian cancer, } \\
\text { metastatic pancreatic cancer, } \\
\text { medulloblastoma, small cell lung } \\
\text { cancer, metastatic prostate cancer, } \\
\text { glioblastoma, and acute myeloid } \\
\text { leukemia }\end{array}$ & $\begin{array}{r}\text { NCT00833417 } \\
\text { NCT01201915 } \\
\text { NCT00739661 } \\
\text { NCT01088815 }\end{array}$ \\
\hline Genistein & Downregulate Glil & Phase $1 / 2$ & Colorectal cancer & NCT01985763 \\
\hline $\begin{array}{l}\text { Sonidegib } \\
\text { (LDE225) }\end{array}$ & SMO inhibitor & Phase $1 / 2$ & $\begin{array}{l}\text { Prostate cancer, ovarian cancer, } \\
\text { pancreatic cancer, and basal cell } \\
\text { carcinoma }\end{array}$ & $\begin{array}{l}\text { NCT02195973 } \\
\text { NCT01487785 } \\
\text { NCT01529450 }\end{array}$ \\
\hline $5 \mathrm{E} 1$ & $\begin{array}{c}\text { Prevent } \mathrm{HH} \\
\text { ligand-Patched binding }\end{array}$ & Preclinical & Prostate cancer & N/A \\
\hline $\begin{array}{l}\text { Glasdegib } \\
\text { (PF-04449913) }\end{array}$ & SMO inhibitor & Phase $1 b / 2$ & $\begin{array}{c}\text { Acute myeloid leukemia, chronic } \\
\text { myelomonocytic leukemia }\end{array}$ & $\begin{array}{l}\text { NCT01841333 } \\
\text { NCT01286467 }\end{array}$ \\
\hline
\end{tabular}

The clinical trial information was accessed via https://clinicaltrials.gov with National Clinical TrialNumber (NCT Number).

tested in clinical trials include additional SMO inhibitors (Saridegib, BMS-833923, Glasdegib, and PF-5274857) and GLI Inhibitor (arsenic trioxide). Other than small molecule inhibitors, a monoclonal antibody, 5E1, blocks binding of all three mammalian $\mathrm{HH}$ ligands to $\mathrm{PTCH}$ for $\mathrm{HH}$ signaling inhibition [68,69]; however, this antibody has not entered clinical trials yet.

2.3. Canonical Notch Signaling. Canonical Notch signaling is another essential evolutionarily conserved pathway in development and adult tissue homeostasis [70]. Notch signaling is activated when the extracellular domain of Notch transmembrane receptor binds to Notch ligands and subsequently induces proteolytic cleavage and release of the intracellular domain (Notch ICD or NICD) of Notch. The Notch ICD then translocates to the nucleus where it interacts with a CBF1/Suppressor of Hairless/LAG-1 (CSL) family DNA-binding protein and regulates the expression of target genes including those pertinent to CSC self-renewal such as Survivin, Myc Nanog, Oct-4, and Sox2 (Figure 2) [71-76]. In mammals, four Notch receptors (Notch 1-Notch 4) and five ligands (Jagged 1 and 2 and Delta-like 1, 3, and 4) have been identified [77].

2.3.1. Abnormal Notch Signaling Activation and CSCs. Abnormal activation of Notch signaling plays a pivotal role in the CSCs of breast cancer, pancreatic cancer, and glioblastoma. For instance, Barnawi et al. reported that fascin (an actinbundling protein) effectively regulates breast CSCs at least partially through Notch pathway [78]. Fascin knockdown significantly reduced breast stem cell-like phenotype (downregulation of stem cell pluripotent genes such as Oct4, Nanog, Sox2, and Klf4), and the cells became less competent in forming colonies and tumorspheres. Conversely, activation of Notch signaling induced the relevant downstream targets predominantly in the fascin-positive cells, and fascin-positive CSCs showed stronger tumorigenesis [78]. In another study, immunohistochemical analysis of 115 breast tumor tissues from primary lesions was performed, and results showed that Notch positive tissues were significantly associated with a CSC marker aldehyde dehydrogenase 1 family member A1 levels [79]. Very recently, Choy et al. reported that Notch 3 signaled constitutively in a panel of basal breast cancer cell lines and in more than one-third of breast basal tumors [80].

Moreover, the important role of Notch signaling was also demonstrated in several other types of CSCs. In a study of patient-derived pancreatic CSCs, Notch ligands Notch 1, Notch 3, Jag1, Jag2, and Notch target gene Hes1 were found to be highly expressed in the pancreatic CSCs, and an inhibitor of $\gamma$-secretase (an important protease mediating Notch signaling by releasing the Notch ICD) significantly decreased the CSC's subpopulation and tumorsphere formation [81]. Moreover, activation of Notch signaling by delta/Serrate/Lag-2 peptide or inhibition of the signaling by knockdown of Hes1 enhanced or decreased pancreatic CSC's tumorsphere formation, respectively [81]. In addition, Notch signaling dysregulation has also been recognized in glioblastoma CSCs [82]. It was found that Protein Kinase C Iota (PKCi) was highly expressed in glioblastoma patientderived CSCs, and silencing PKCi resulted in apoptosis and reduction of proliferation of the glioblastoma CSCs in vitro and tumor growth in vivo in a xenograft mouse model [83]. Gene expression profiling of PKCi-silenced glioblastoma CSCs revealed a novel role of the Notch signaling pathway in PKCi mediated glioblastoma CSC's survival [83]. In addition to its important roles in CSCs, Notch signaling is also involved in EMT to promote cancer cell acquisition of a stemlike phenotype and drug resistance. For instance, prostate cancer cells undergoing EMT displayed stem-like cell features characterized by increased expression of Notch 1 and other pluripotent genes such as Sox2, Nanog, Oct4, and Lin28 [84].

2.3.2. Therapeutic Agents Targeting Notch Signaling. Therapeutics targeting the Notch pathway mostly consist of $\gamma$-secretase inhibitors and anti-DLL4 antibodies (Table 3). Inhibition of the Notch pathway via $\gamma$-secretase inhibitors prevents 
TABLE 3: Small molecule/biological therapeutics targeting the Notch pathway.

\begin{tabular}{lcccc}
\hline Molecule & Function & $\begin{array}{c}\text { Phase/clinical } \\
\text { trials }\end{array}$ & Cancer type & NCT Number \\
\hline RO4929097 & $\begin{array}{c}\text { Gamma secretase } \\
\text { inhibitor }\end{array}$ & Phase 2 & $\begin{array}{c}\text { Breast cancer, ovarian cancer, renal } \\
\text { cell carcinoma }\end{array}$ & NCT01131234 \\
\hline LY900009 & $\begin{array}{c}\text { Gamma secretase } \\
\text { inhibitor }\end{array}$ & Phase 1 & Advanced solid tumor or lymphoma & NCT01158404 \\
\hline PF-03084014 & $\begin{array}{c}\text { Gamma secretase } \\
\text { inhibitor }\end{array}$ & Phase 1/2 & $\begin{array}{c}\text { T-cell acute lymphoblastic leukemia } \\
\text { and T-cell lymphoblastic lymphoma }\end{array}$ & $\begin{array}{c}\text { NCT00878189 } \\
\text { NCT01981551 }\end{array}$ \\
\hline Enoticumab & Anti-DLL4 antibody & Phase 1 & Advanced solid tumors and ovarian & NCT00871559 \\
\hline Demcizumab & Anti-DLL4 antibody & Phase 1b/2 & $\begin{array}{c}\text { Advanced solid tumors, pancreatic } \\
\text { cancer, ovarian cancer, and } \\
\text { non-small cell lung cancer }\end{array}$ & $\begin{array}{c}\text { NCT02722954 } \\
\text { NCT01189968 } \\
\text { NCT01189929 }\end{array}$ \\
\hline Tarextumab & Anti-Notch 2/3 & Phase 1b/2 & $\begin{array}{c}\text { Solid tumors, Stage IV pancreatic } \\
\text { cancer, and Stage IV small cell lung } \\
\text { cancer }\end{array}$ & $\begin{array}{c}\text { NCT01277146 } \\
\text { NCT01647828 } \\
\text { NCT01859741 }\end{array}$ \\
\hline
\end{tabular}

The clinical trial information was accessed via https://clinicaltrials.gov with National Clinical TrialNumber (NCT Number).

Notch receptor cleavage at the cell surface, thus blocking activation of self-renewal target genes. In a preclinical study, a $\gamma$-secretase inhibitor RO4929097 significantly suppressed Notch target genes Hesl, Heyl, and HeyL [85]. Several phase I and phase II studies have been conducted in hopes of synergistically utilizing RO4929097 with other agents for cancer treatment. For instance, in a completed phase I trial, RO4929097 and Cediranib Maleate were used in tandem to determine the phase II dose and safety profile of RO4929097 in solid tumors (NCT Number: NCT01131234), and the clinical trial data shall be announced soon. Another $\gamma$ secretase inhibitor is LY900009, developed by Eli Lilly, which is in phase I for patients with advanced cancer including leiomyosarcoma and ovarian cancer [86]. A third $\gamma$-secretase inhibitor (PF-003084014) was developed by Pfizer, and it is progressing in its phase I trials in patients with T-cell acute lymphoblastic leukemia and T-cell lymphoblastic lymphoma [87]. In addition to $\gamma$-secretase inhibitors, another category of Notch pathway molecules is monoclonal antibodies that target DLL4 (Delta-like ligand 4) to prevent ligand binding. Enoticumab (REGN421) is an anti-DLL4 antibody that has been used to target advanced solid tumors with overexpression of DLL4 (such as ovarian cancer) [88]. In 2015, a recommended phase II dose of $4 \mathrm{mg} / \mathrm{kg}$ every 3 weeks or $3 \mathrm{mg} / \mathrm{kg}$ every 2 weeks administered intravenously was established based on PK profiles in patients diagnosed with ovarian, colon, or breast cancer. [89]. Another anti-DLL4 monoclonal antibody developed by OncoMed Pharmaceuticals and Celgene is Demcizumab, which has recently completed a phase I dose escalation clinical trial as well. In this study, Demcizumab was well tolerated at doses $\leq 5 \mathrm{mg}$ with disease stabilization and tumor size decreases when administered weekly. The side effects of Demcizumab include hypertension and an increased risk of congestive heart failure in prolonged drug administration (NCT Number: NCT02722954) [90].

\section{Crosstalk among Pathways and Combination Treatments}

Many pathways do not act as isolated units but rather often interact with other pathways as a biological network during development and homeostasis. Crosstalk among Wnt, $\mathrm{HH}$, Notch, and other pathways have been reported in cancer and CSCs [91]. For instance, in a colorectal cancer study, progastrin secreted by colorectal tumors was shown to activate Wnt signaling and result in expression of Wnt target genes including Jagged-1, one Notch ligand. Upregulation of Jagged-1 induces Notch signaling which in turn may further elevate $\beta$-catenin activity of progastrin-driven Wnt and Notch signaling in colorectal cancer cells [92]. Similarly, in breast CSCs, Mel-18 was reported as a negative regulator of breast CSC's self-renewal. Knockdown of Mel-18 increased Wnt signaling, which subsequently upregulated Wnt target gene jagged-1's expression, leading to activation of the Notch pathway for CSC's self-renewal [93]. In addition, HH signaling can crosstalk with both Wnt and Notch pathways as well. In gastric cancer cells, $\mathrm{HH}$ signaling was shown to suppress Wnt signaling through the soluble frizzled-related protein 1 ( $\mathrm{sFrP1}$ ), a target gene of $\mathrm{HH}$ signaling capable of modulating Wnt pathway by directly binding to Wnt ligands [94]. In another study of glioblastoma cells and patient specimens, Notch signaling inhibition was shown to downregulate its target gene Hes1 which in turn upregulates GLI transcription in the $\mathrm{HH}$ pathway [95].

Complex signaling networks are known to contribute to the cellular diversity of stem cells during embryogenesis and tissue homeostasis and may play essential roles in the cancer and CSC's biology. In recent years, significant efforts have been made to develop combination therapies to target multiple signaling pathways for cancer treatments. For instance, a recent study demonstrated that combination inhibition of both Notch and $\mathrm{HH}$ signaling depleted the CSC 
subpopulation cells in a prostate cancer model [96]. In addition, a clinical trial of combination of $\mathrm{HH}$ pathway inhibitor Vismodegib and Notch signaling inhibitor RO4929097 has been conducted in patients with advanced breast and sarcoma. In another recent study, Sharma et al. showed that combination treatment with $\mathrm{HH}$ signaling inhibitor NVP-LDE225 and pI3/mTOR/Akt signaling inhibitor NVPBEZ235 inhibited self-renewal capacity of pancreatic CSCs by suppressing the expression of pluripotency maintaining factors Nanog, Oct-4, Sox-2, and c-Myc and transcription of GLI [97].

\section{Conclusions}

Since the first identification of CSCs in leukemia, the important roles of CSCs in cancer progression, metastasis, and relapse as well as drug resistance have been increasingly recognized. Eradication of CSCs by targeting the key signaling pathways underlying CSC's stemness and function represents a promising approach in cancer treatment. In this review, we mainly summarized the three critical evolutionarily conserved pathways (Wnt, $\mathrm{HH}$, and Notch signaling) in CSCs and potential therapies targeting these pathways for cancer treatment. To date, numerous agents have been developed to specifically target each of these pathways for cancer treatments. Nevertheless, it has been recognized that the signaling pathways may interact with each other as a coordinated network to regulate CSC stemness and functions. Therefore, understanding the crosstalk among the signaling pathways in CSC regulation is critical for the development of therapies targeting CSCs.

\section{Competing Interests}

The authors declare no competing financial interests.

\section{Acknowledgments}

This work was supported by the seed fund of College of Veterinary Medicine and intramural grant at Western University of Health Sciences to Jijun Hao and the National Natural Science Foundation of China (nos. 81272444 and 81472744 to Li Zhong).

\section{References}

[1] T. Lapidot, C. Sirard, J. Vormoor et al., "A cell initiating human acute myeloid leukaemia after transplantation into SCID mice," Nature, vol. 367, no. 6464, pp. 645-648, 1994.

[2] D. Bonnet and J. E. Dick, "Human acute myeloid leukemia is organized as a hierarchy that originates from a primitive hematopoietic cell," Nature Medicine, vol. 3, no. 7, pp. 730-737, 1997.

[3] S. K. Singh, C. Hawkins, I. D. Clarke et al., "Identification of human brain tumour initiating cells," Nature, vol. 432, no. 7015, pp. 396-401, 2004.

[4] D. Fang, T. K. Nguyen, K. Leishear et al., "A tumorigenic subpopulation with stem cell properties in melanomas," Cancer Research, vol. 65, no. 20, pp. 9328-9337, 2005.

[5] M. Al-Hajj, M. S. Wicha, A. Benito-Hernandez, S. J. Morrison, and M. F. Clarke, "Prospective identification of tumorigenic breast cancer cells," Proceedings of the National Academy of Sciences of the United States of America, vol. 100, no. 7, pp. 39833988, 2003.

[6] S. Ma, K.-W. Chan, L. Hu et al., "Identification and characterization of tumorigenic liver cancer stem/progenitor cells," Gastroenterology, vol. 132, no. 7, pp. 2542-2556, 2007.

[7] C. Li, D. G. Heidt, P. Dalerba et al., "Identification of pancreatic cancer stem cells," Cancer Research, vol. 67, no. 3, pp. 1030-1037, 2007.

[8] C. A. O’Brien, A. Pollett, S. Gallinger, and J. E. Dick, "A human colon cancer cell capable of initiating tumour growth in immunodeficient mice," Nature, vol. 445, no. 7123, pp. 106-110, 2007.

[9] A. T. Collins, P. A. Berry, C. Hyde, M. J. Stower, and N. J. Maitland, "Prospective identification of tumorigenic prostate cancer stem cells," Cancer Research, vol. 65, no. 23, pp. 1094610951, 2005.

[10] G. Liu, X. Yuan, Z. Zeng et al., "Analysis of gene expression and chemoresistance of CD133+ cancer stem cells in glioblastoma," Molecular Cancer, vol. 5, article no. 67, 2006.

[11] C. Delude, "Tumorigenesis: testing ground for cancer stem cells," Nature, vol. 480, no. 7377, pp. S43-S45, 2011.

[12] J. Chen, Y. Li, T.-S. Yu et al., "A restricted cell population propagates glioblastoma growth after chemotherapy," Nature, vol. 488, no. 7412, pp. 522-526, 2012.

[13] N. D. Marjanovic, R. A. Weinberg, and C. L. Chaffer, "Cell plasticity and heterogeneity in cancer," Clinical Chemistry, vol. 59, no. 1, pp. 168-179, 2013.

[14] S. Schwitalla, "Tumor cell plasticity: the challenge to catch a moving target," Journal of Gastroenterology, vol. 49, no. 4, pp. 618-627, 2014.

[15] R. M. Bachoo, E. A. Maher, K. L. Ligon et al., "Epidermal growth factor receptor and Ink4a/Arf: convergent mechanisms governing terminal differentiation and transformation along the neural stem cell to astrocyte axis," Cancer Cell, vol. 1, no. 3, pp. 269-277, 2002.

[16] D. Friedmann-Morvinski, E. A. Bushong, E. Ke et al., "Dedifferentiation of neurons and astrocytes by oncogenes can induce gliomas in mice," Science, vol. 338, no. 6110, pp. 1080-1084, 2012.

[17] S. Schwitalla, A. A. Fingerle, P. Cammareri et al., "Intestinal tumorigenesis initiated by dedifferentiation and acquisition of stem-cell-like properties," Cell, vol. 152, no. 1-2, pp. 25-38, 2013.

[18] B. Tang, G. Qi, F. Tang et al., "Aberrant JMJD3 Expression Upregulates Slug to Promote Migration, Invasion, and Stem Cell-Like Behaviors in Hepatocellular Carcinoma," Cancer Research, vol. 76, no. 22, pp. 6520-6532, 2016.

[19] A. Martin and A. Cano, "Tumorigenesis: Twistl links EMT to self-renewal," Nature Cell Biology, vol. 12, no. 10, pp. 924-925, 2010.

[20] Y. Komiya and R. Habas, "Wnt signal transduction pathways," Organogenesis, vol. 4, no. 2, pp. 68-75, 2008.

[21] H. Clevers, "Wnt/ $\beta$-catenin signaling in development and disease," Cell, vol. 127, no. 3, pp. 469-480, 2006.

[22] B. T. MacDonald, K. Tamai, and X. He, "Wnt/ $\beta$-catenin signaling: components, mechanisms, and diseases," Developmental Cell, vol. 17, no. 1, pp. 9-26, 2009.

[23] S. Basu, G. Haase, and A. Ben-Ze'ev, "Wnt signaling in cancer stem cells and colon cancer metastasis," F1000Research, vol. 5, article no. 699, 2016.

[24] S. Mukherjee, M. Mazumdar, S. Chakraborty et al., "Curcumin inhibits breast cancer stem cell migration by amplifying the 
E-cadherin/ $\beta$-catenin negative feedback loop," Stem Cell Research and Therapy, vol. 5, no. 5, article 116, 2014.

[25] T. Reya, A. W. Duncan, L. Ailles et al., "A role for Wnt signalling in self-renewal of haematopoietic stem cells," Nature, vol. 423, no. 6938, pp. 409-414, 2003.

[26] X. Zhang, Y. Lou, H. Wang et al., "Wnt signaling regulates the stemness of lung cancer stem cells and its inhibitors exert anticancer effect on lung cancer SPC-A1 cells," Medical Oncology, vol. 32, no. 4, article 95, 2015.

[27] I. Malanchi, H. Peinado, D. Kassen et al., "Cutaneous cancer stem cell maintenance is dependent on $\beta$-catenin signalling," Nature, vol. 452, no. 7187, pp. 650-653, 2008.

[28] L. E. Dow, K. P. O’Rourke, J. Simon et al., “Apc restoration promotes cellular differentiation and reestablishes crypt homeostasis in colorectal cancer," Cell, vol. 161, no. 7, pp. 1539-1552, 2015.

[29] L. N. Kwong and W. F. Dove, "APC and its modifiers in colon cancer," Advances in Experimental Medicine and Biology, vol. 656, pp. 85-106, 2009.

[30] W. S. Samowitz, M. L. Slattery, C. Sweeney, J. Herrick, R. K. Wolff, and H. Albertsen, "APC mutations and other genetic and epigenetic changes in colon cancer," Molecular Cancer Research, vol. 5, no. 2, pp. 165-170, 2007.

[31] N. Zhang, Y. Jiang, J. Zou, S. Zhuang, H. Jin, and Q. Yu, "Insights into unbinding mechanisms upon two mutations investigated by molecular dynamics study of GSK3 $\beta$-axin complex: role of packing hydrophobic residues," Proteins: Structure, Function and Genetics, vol. 67, no. 4, pp. 941-949, 2007.

[32] J. P. Medema and L. Vermeulen, "Microenvironmental regulation of stem cells in intestinal homeostasis and cancer," Nature, vol. 474, no. 7351, pp. 318-326, 2011.

[33] S. Zhang, Z. Huang, L. Li, J. Fu, and B. Xiao, "Identification of CD200+ colorectal cancer stem cells and their gene expression profile," Oncology Reports, vol. 36, no. 4, pp. 2252-2260, 2016.

[34] D. Liu, L. Du, D. Chen et al., "Reduced CD146 expression promotes tumorigenesis and cancer stemness in colorectal cancer through activating Wnt/ $\beta$-catenin signaling," Oncotarget, vol. 7, no. 26, pp. 40704-40718, 2016.

[35] X. Zhang and J. Hao, "Development of anticancer agents targeting the Wnt/beta-catenin signaling," American Journal of Cancer Research, vol. 5, no. 8, pp. 2344-2360, 2015.

[36] K. H. Emami, C. Nguyen, H. Ma et al., "A small molecule inhibitor of beta-catenin/CREB-binding protein transcription," Proceedings of the National Academy of Sciences of the United States of America, vol. 101, no. 34, pp. 12682-12687, 2004.

[37] A. B. El-Khoueiry, Y. Ning, D. Yang et al., "A phase I firstin-human study of PRI-724 in patients (pts) with advanced solid tumors," Journal of Clinical Oncology, vol. 31, supplement, abstract 2501, 2013, Proceedings of the 2013 ASCO Annual Meeting.

[38] S. Biechele, B. J. Cox, and J. Rossant, "Porcupine homolog is required for canonical Wnt signaling and gastrulation in mouse embryos," Developmental Biology, vol. 355, no. 2, pp. 275-285, 2011.

[39] J. J. Barrott, G. M. Cash, A. P. Smith, J. R. Barrow, and L. C. Murtaugh, "Deletion of mouse Porcn blocks Wnt ligand secretion and reveals an ectodermal etiology of human focal dermal hypoplasia/Goltz syndrome," Proceedings of the National Academy of Sciences of the United States of America, vol. 108, no. 31, pp. 12752-12757, 2011.
[40] J. Liu, S. Pan, M. H. Hsieh et al., "Targeting Wnt-driven cancer through the inhibition of Porcupine by LGK974," Proceedings of the National Academy of Sciences of the United States of America, vol. 110, no. 50, pp. 20224-20229, 2013.

[41] K. P. Papadopoulos, L. Rosen, R. Chugh et al., "A phase Ia study in patients with advanced solid tumors for the human monoclonal antibody vantictumab (OMP-18R5; anti-Frizzled) targeting the WNT pathway," European Journal of Cancer, vol. 49, p. S188, 2013.

[42] D. C. Smith, L. Rosen, R. Chugh et al., "First-in-human evaluation of the human monoclonal antibody vantictumab (OMP18R5; anti-Frizzled) targeting the WNT pathway in a phase I study for patients with advanced solid tumors," Journal of Clinical Oncology, vol. 31, 15, supplement, abstract 2540, 2013, Proceedings of the 2013 ASCO Annual Meeting.

[43] Z. Jin, T. Schwend, J. Fu et al., "Members of the Rusc protein family interact with Sufu and inhibit vertebrate Hedgehog signaling," Development, vol. 143, no. 21, pp. 3944-3955, 2016.

[44] M. Varjosalo and J. Taipale, "Hedgehog: functions and mechanisms," Genes and Development, vol. 22, no. 18, pp. 2454-2472, 2008.

[45] J. G. Habib and J. A. O'Shaughnessy, "The hedgehog pathway in triple-negative breast cancer," Cancer Medicine, vol. 5, no. 10, pp. 2989-3006, 2016.

[46] V. Justilien and A. P. Fields, "Molecular pathways: novel approaches for improved therapeutic targeting of hedgehog signaling in cancer stem cells," Clinical Cancer Research, vol. 21, no. 3, pp. 505-513, 2015.

[47] K. E. Ryan and C. Chiang, "Hedgehog secretion and signal transduction in vertebrates," Journal of Biological Chemistry, vol. 287, no. 22, pp. 17905-17913, 2012.

[48] A. A. Merchant and W. Matsui, "Targeting Hedgehog-a cancer stem cell pathway," Clinical Cancer Research, vol. 16, no. 12, pp. 3130-3140, 2010.

[49] V. Clement, P. Sanchez, N. de Tribolet, I. Radovanovic, and A. Ruiz i Altaba, "HEDGEHOG-GLI1 signaling regulates human glioma growth, cancer stem cell self-renewal, and tumorigenicity," Current Biology, vol. 17, no. 2, pp. 165-172, 2007.

[50] E. E. Bar, A. Chaudhry, A. Lin et al., "Cyclopamine-mediated Hedgehog pathway inhibition depletes stem-like cancer cells in glioblastoma," Stem Cells, vol. 25, no. 10, pp. 2524-2533, 2007.

[51] C. Dierks, R. Beigi, G.-R. Guo et al., "Expansion of Bcr-Ablpositive leukemic stem cells is dependent on hedgehog pathway activation," Cancer Cell, vol. 14, no. 3, pp. 238-249, 2008.

[52] C. Zhao, A. Chen, C. H. Jamieson et al., "Hedgehog signalling is essential for maintenance of cancer stem cells in myeloid leukaemia," Nature, vol. 458, no. 7239, pp. 776-779, 2009.

[53] V. Justilien, M. P. Walsh, S. A. Ali, E. A. Thompson, N. R. Murray, and A. P. Fields, "The PRKCI and SOX2 oncogenes are coamplified and cooperate to activate hedgehog signaling in lung squamous cell carcinoma," Cancer Cell, vol. 25, no. 2, pp. 139-151, 2014.

[54] C. D. Peacock, Q. Wang, G. S. Gesell et al., "Hedgehog signaling maintains a tumor stem cell compartment in multiple myeloma," Proceedings of the National Academy of Sciences of the United States of America, vol. 104, no. 10, pp. 4048-4053, 2007.

[55] B.-E. Batsaikhan, K. Yoshikawa, N. Kurita et al., "Cyclopamine decreased the expression of sonic hedgehog and its downstream genes in colon cancer stem cells," Anticancer Research, vol. 34, no. 11, pp. 6339-6344, 2014. 
[56] F.-T. Huang, Y.-X. Zhuan-Sun, Y.-Y. Zhuang et al., "Inhibition of hedgehog signaling depresses self-renewal of pancreatic cancer stem cells and reverses chemoresistance," International Journal of Oncology, vol. 41, no. 5, pp. 1707-1714, 2012.

[57] S. Singh, D. Chitkara, R. Mehrazin, S. W. Behrman, R. W. Wake, and R. I. Mahato, "Chemoresistance in prostate cancer cells is regulated by miRNAs and Hedgehog pathway," PLoS ONE, vol. 7, no. 6, Article ID e40021, 2012.

[58] D. N. Watkins, D. M. Berman, S. G. Burkholder, B. Wang, P. A. Beachy, and S. B. Baylin, "Hedgehog signalling within airway epithelial progenitors and in small-cell lung cancer," Nature, vol. 422, no. 6929, pp. 313-317, 2003.

[59] S. A. Colavito, M. R. Zou, Q. Yan, D. X. Nguyen, and D. F. Stern, "Significance of glioma-associated oncogene homolog 1 (GLI1) expression in claudin-low breast cancer and crosstalk with the nuclear factor kappa-light-chain-enhancer of activated B cells (NFאB) pathway," Breast Cancer Research, vol. 16, no. 5, article 444, 2014.

[60] F. Wang, L. Ma, Z. Zhang et al., "Hedgehog signaling regulates epithelial-mesenchymal transition in pancreatic cancer stemlike cells," Journal of Cancer, vol. 7, no. 4, pp. 408-417, 2016.

[61] T. K. Rimkus, R. L. Carpenter, S. Qasem, M. Chan, and H.-W. Lo, "Targeting the sonic hedgehog signaling pathway: review of smoothened and GLI inhibitors," Cancers, vol. 8, no. 2, article no. 3, 2016.

[62] J. M. Ruch and E. J. Kim, "Hedgehog signaling pathway and cancer therapeutics: progress to date," Drugs, vol. 73, no. 7, pp. 613-623, 2013.

[63] E. Petricci and F. Manetti, “Targeting the hedgehog signaling pathway with small molecules from natural sources," Current Medicinal Chemistry, vol. 22, no. 35, pp. 4058-4090, 2015.

[64] D. D. Von Hoff, P. M. LoRusso, C. M. Rudin et al., "Inhibition of the hedgehog pathway in advanced basal-cell carcinoma," The New England Journal of Medicine, vol. 361, no. 12, pp. 1164-1172, 2009.

[65] A. Sekulic, M. R. Migden, A. E. Oro et al., "Efficacy and safety of vismodegib in advanced basal-cell carcinoma," New England Journal of Medicine, vol. 366, no. 23, pp. 2171-2179, 2012.

[66] H. Q. Doan, S. Silapunt, and M. R. Migden, "Sonidegib, a novel smoothened inhibitor for the treatment of advanced basal cell carcinoma," Journal of OncoTargets and Therapy, vol. 9, pp. 5671-5678, 2016.

[67] R. Dummer, A. Guminski, R. Gutzmer et al., "The 12-month analysis from Basal Cell Carcinoma Outcomes with LDE225 Treatment (BOLT): a phase II, randomized, double-blind study of sonidegib in patients with advanced basal cell carcinoma," Journal of the American Academy of Dermatology, vol. 75, no. 1, pp. 113-125.e5, 2016.

[68] J. Ericson, S. Morton, A. Kawakami, H. Roelink, and T. M. Jessell, "Two critical periods of Sonic Hedgehog signaling required for the specification of motor neuron identity," Cell, vol. 87, no. 4, pp. 661-673, 1996.

[69] I. Bosanac, H. R. Maun, S. J. Scales et al., "The structure of SHH in complex with HHIP reveals a recognition role for the Shh pseudo active site in signaling," Nature Structural and Molecular Biology, vol. 16, no. 7, pp. 691-697, 2009.

[70] S. Artavanis-Tsakonas, M. D. Rand, and R. J. Lake, "Notch signaling: cell fate control and signal integration in development," Science, vol. 284, no. 5415, pp. 770-776, 1999.

[71] Y. Chen, D. Li, H. Liu et al., "Notch-1 signaling facilitates survivin expression in human non-small cell lung cancer cells," Cancer Biology and Therapy, vol. 11, no. 1, pp. 14-21, 2011.
[72] J.-B. Yu, H. Jiang, and R.-Y. Zhan, "Aberrant Notch signaling in glioblastoma stem cells contributes to tumor recurrence and invasion," Molecular Medicine Reports, vol. 14, no. 2, pp. 12631268, 2016.

[73] A. Klinakis, M. Szaboks, K. Politi, H. Kiaris, S. ArtavanisTsakonas, and A. Efstratiadis, "Myc is a Notchl transcriptional target and a requisite for Notch1-induced mammary tumorigenesis in mice," Proceedings of the National Academy of Sciences of the United States of America, vol. 103, no. 24, pp. 9262-9267, 2006.

[74] T. Palomero, K. L. Wei, D. T. Odom et al., "NOTCH1 directly regulates c-MYC and activates a feed-forward-loop transcriptional network promoting leukemic cell growth," Proceedings of the National Academy of Sciences of the United States of America, vol. 103, no. 48, pp. 18261-18266, 2006.

[75] B. Kim, N. Jung, S. Lee, J. K. Sohng, and H. J. Jung, "Apigenin inhibits cancer stem cell-like phenotypes in human glioblastoma cells via suppression of c-met signaling," Phytotherapy Research, vol. 30, no. 11, pp. 1833-1840, 2016.

[76] E. R. Andersson, R. Sandberg, and U. Lendahl, "Notch signaling: simplicity in design, versatility in function," Development, vol. 138, no. 17, pp. 3593-3612, 2011.

[77] L. Miele, "Notch signaling," Clinical Cancer Research, vol. 12, no. 4, pp. 1074-1079, 2006.

[78] R. Barnawi, S. Al-Khaldi, G. Majed Sleiman et al., "Fascin is critical for the maintenance of breast cancer stem cell pool predominantly via the activation of the notch self-renewal pathway," Stem Cells, vol. 34, no. 12, pp. 2799-2813, 2016.

[79] Y. Zhong, S. Shen, Y. Zhou et al., "NOTCH1 is a poor prognostic factor for breast cancer and is associated with breast cancer stem cells," OncoTargets and Therapy, vol. 9, pp. 6865-6871, 2016.

[80] L. Choy, T. Hagenbeek, M. Solon et al., "Constitutive NOTCH3 signaling promotes the growth of basal breast cancers," Cancer Research, 2017.

[81] E. V. Abel, E. J. Kim, J. Wu et al., “The notch pathway is important in maintaining the cancer stem cell population in pancreatic cancer," PLoS ONE, vol. 9, no. 3, Article ID e91983, 2014.

[82] T. Seymour, A. Nowak, and F. Kakulas, “Targeting aggressive cancer stem cells in glioblastoma," Frontiers in Oncology, vol. 5, article no. 159, 2015.

[83] E. Phillips, V. Lang, J. Bohlen et al., "Targeting atypical protein kinase $C$ iota reduces viability in glioblastoma stem-like cells via a notch signaling mechanism," International Journal of Cancer, vol. 139, no. 8, pp. 1776-1787, 2016.

[84] D. Kong, S. Banerjee, A. Ahmad et al., "Epithelial to mesenchymal transition is mechanistically linked with stem cell signatures in prostate cancer cells," PLoS ONE, vol. 5, no. 8, Article ID e12445, 2010.

[85] B. G. Debeb, E. N. Cohen, K. Boley et al., "Pre-clinical studies of Notch signaling inhibitor RO4929097 in inflammatory breast cancer cells," Breast Cancer Research and Treatment, vol. 134, no. 2, pp. 495-510, 2012.

[86] S. Pant, S. F. Jones, C. D. Kurkjian et al., "A first-in-human phase I study of the oral Notch inhibitor, LY900009, in patients with advanced cancer," European Journal of Cancer, vol. 56, pp. 1-9, 2016.

[87] C. Papayannidis, D. J. DeAngelo, W. Stock et al., "A phase 1 study of the novel gamma-secretase inhibitor PF-03084014 in patients with T-cell acute lymphoblastic leukemia and T-cell lymphoblastic lymphoma," Blood Cancer Journal, vol. 5, no. 9, article e350, 2015. 
[88] J. Huang, W. Hu, L. Hu et al., "Dll4 inhibition plus aflibercept markedly reduces ovarian tumor growth," Molecular Cancer Therapeutics, vol. 15, no. 6, pp. 1344-1352, 2016.

[89] E. G. Chiorean, P. LoRusso, R. M. Strother et al., "A phase I first-in-human study of enoticumab (REGN421), a fully human delta-like ligand 4 (Dll4) monoclonal antibody in patients with advanced solid tumors," Clinical Cancer Research, vol. 21, no. 12, pp. 2695-2703, 2015.

[90] D. C. Smith, P. D. Eisenberg, G. Manikhas et al., "A phase I dose escalation and expansion study of the anticancer stem cell agent demcizumab (Anti-DLL4) in patients with previously treated solid tumors," Clinical Cancer Research, vol. 20, no. 24, pp. 62956303, 2014.

[91] M. Katoh, "Networking of WNT, FGF, Notch, BMP, and Hedgehog signaling pathways during carcinogenesis," Stem Cell Reviews, vol. 3, no. 1, pp. 30-38, 2007.

[92] J. Pannequin, C. Bonnans, N. Delaunay et al., “The Wnt target jagged-1 mediates the activation of notch signaling by progastrin in human colorectal cancer cells," Cancer Research, vol. 69, no. 15, pp. 6065-6073, 2009.

[93] H.-Y. Won, J.-Y. Lee, D.-H. Shin et al., "Loss of Mel-18 enhances breast cancer stem cell activity and tumorigenicity through activating Notch signaling mediated by the Wnt/TCF pathway," The FASEB Journal, vol. 26, no. 12, pp. 5002-5013, 2012.

[94] J. He, T. Sheng, A. A. Stelter et al., "Suppressing Wnt signaling by the hedgehog pathway through sFRP-1," The Journal of Biological Chemistry, vol. 281, no. 47, pp. 35598-35602, 2006.

[95] K. C. Schreck, P. Taylor, L. Marchionni et al., "The Notch target Hesl directly modulates Glil expression and hedgehog signaling: a potential mechanism of therapeutic resistance," Clinical Cancer Research, vol. 16, no. 24, pp. 6060-6070, 2010.

[96] J. Domingo-Domenech, S. J. Vidal, V. Rodriguez-Bravo et al., "Suppression of acquired docetaxel resistance in prostate cancer through depletion of notch- and hedgehog-dependent tumorinitiating cells," Cancer Cell, vol. 22, no. 3, pp. 373-388, 2012.

[97] N. Sharma, R. Nanta, J. Sharma et al., "PI3K/AKT/mTOR and sonic hedgehog pathways cooperate together to inhibit human pancreatic cancer stem cell characteristics and tumor growth," Oncotarget, vol. 6, no. 31, pp. 32039-32060, 2015. 

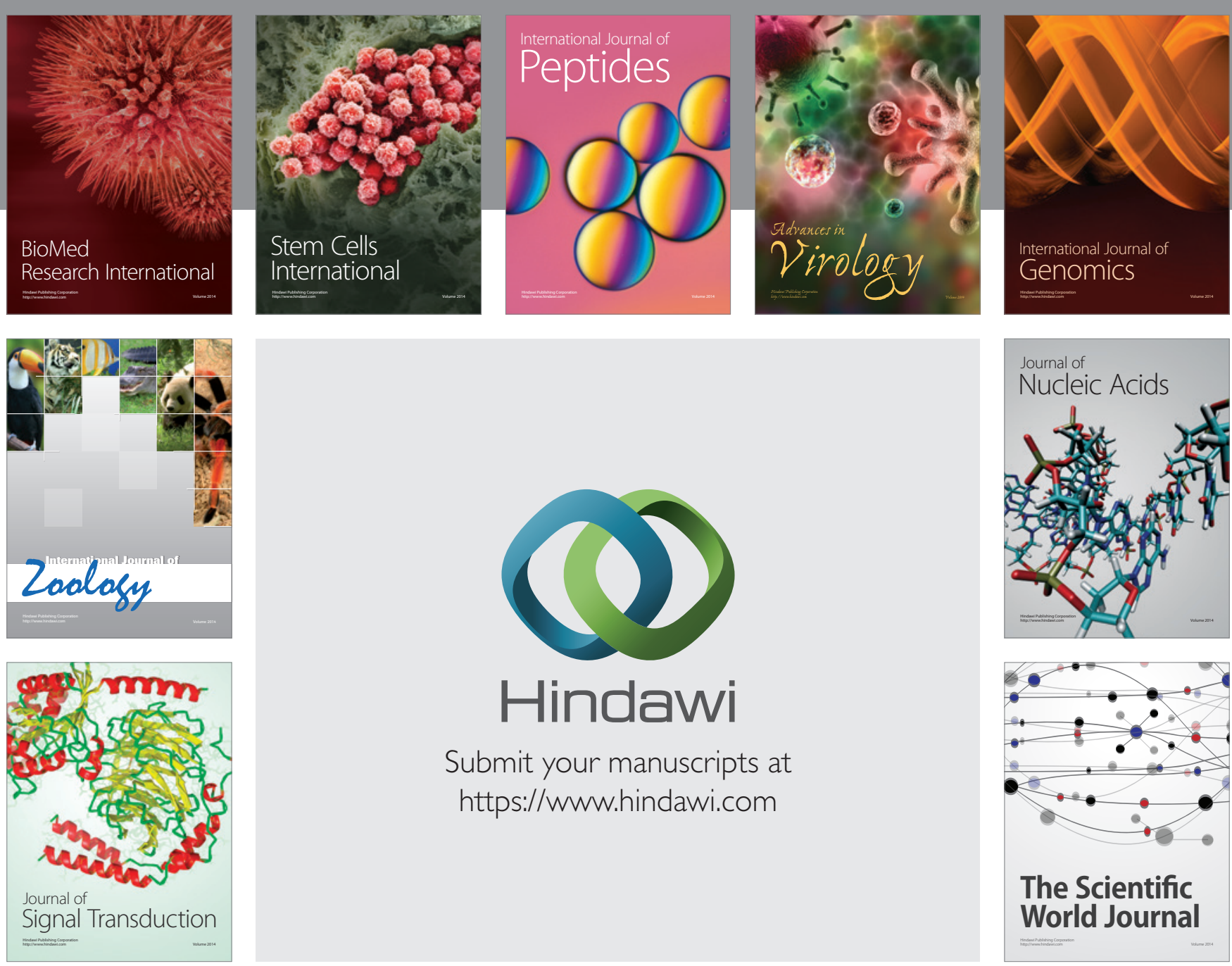

Submit your manuscripts at

https://www.hindawi.com
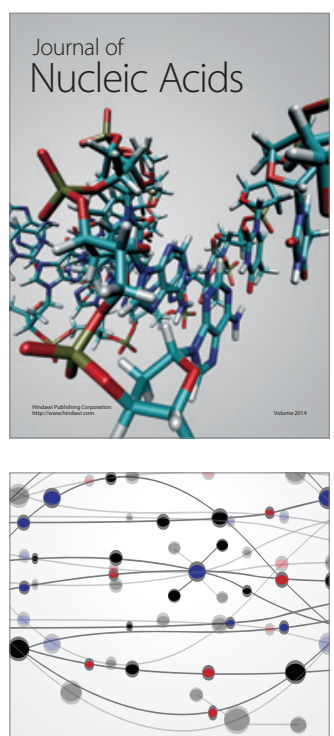

The Scientific World Journal
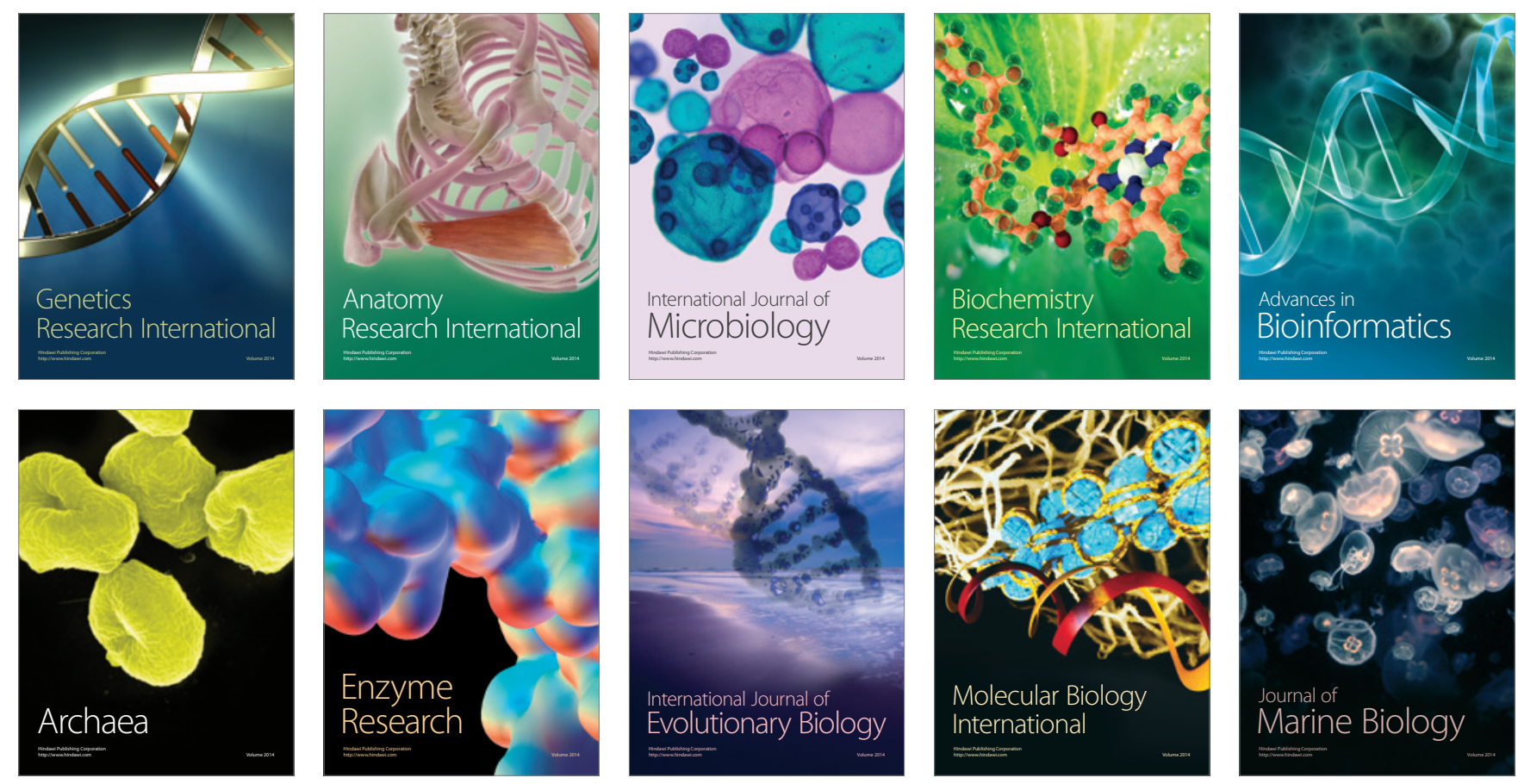